\title{
Stigma and Non-Disclosure in Psychiatric Patients from a Southeast Asian Hospital
}

\author{
Leslie Lim¹, Justine Goh ${ }^{1}$, Yiong-Huak Chan ${ }^{2}$ \\ ${ }^{1}$ Department of Psychiatry, Singapore General Hospital, Singapore, Singapore \\ ${ }^{2}$ National University Health System, Singapore, Singapore \\ Email: leslie.lim.e.c@singhealth.com.sg
}

How to cite this paper: Lim, L., Goh, J. and Chan, Y.-H. (2018) Stigma and NonDisclosure in Psychiatric Patients from a Southeast Asian Hospital. Open Journal of Psychiatry, 8, 80-90. https://doi.org/10.4236/ojpsych.2018.81007

Received: December 8, 2017

Accepted: January 9, 2018

Published: January 12, 2018

Copyright $\odot 2018$ by authors and Scientific Research Publishing Inc. This work is licensed under the Creative Commons Attribution International License (CC BY 4.0).

http://creativecommons.org/licenses/by/4.0/

(c) (i) Open Access

\begin{abstract}
Objective: We compared stigma experienced by psychiatric patients and controls in various social domains and hypothesized higher levels of stigma and higher rates of non-disclosure by psychiatric patients. Methods: Psychiatric outpatients and a control group of medical outpatients were assessed for experienced discrimination through a structured questionnaire that included adapted items from the Discrimination and Stigma Scale (DISC-12). Controls were assessed on discrimination related to physical, rather than mental health issues. Statistical analyses were conducted with Pearson's chi-squared tests and one-way Analyses of Variance (ANOVA). Results: In total, 202 patients comprising 99 psychiatric patients and 103 controls gave consent to the study. Psychiatric patients experienced higher levels of discrimination $(F(1,196)=24.4, p<0.001)$, and in more areas of life $(F(1,196)=22.5, p<0.001)$ than controls. Compared to controls, a higher proportion of psychiatric patients practised non-disclosure of their illness. Conclusion: Our study confirmed that psychiatric patients experienced considerable stigma and coped by non-disclosure of their condition.
\end{abstract}

\section{Keywords}

Psychiatric Patients, Medical Patients, Stigma, Discrimination, Non-Disclosure, Embarrassment

\section{Introduction}

Persons suffering from mental illness are among the most stigmatized, discriminated against, and disadvantaged members of society [1]. The general public often allows stigma to guide their attitudes and behavior towards people with mental illness. Factors that contribute to stigma include symptoms of severe mental ill- 
ness [2] [3] [4], poor social skills arising from mental illness [5] [6], or even poor personal appearance [7] [8].

Such negative attitudes can lead to discrimination experienced in various social domains, such as personal relationships, education, and work [9] [10] [11]. Unsurprisingly, stigma has been identified as a significant barrier to effective care [11] [12] [13], with low rates of help seeking and undertreatment [3] [14] [15].

Stigma is prevalent in Asian societies, with some suggesting that it could be as problematic as in Western societies [16]. Local studies have assessed the perception of the general public towards the mentally ill. Some have found that more than one third (38\%) of the general population believed that people with psychiatric disorders were dangerous [17] and unpredictable [18].

While previous local research studied discriminatory attitudes by members of the general population [17] [18], this is one of the few studies to assess stigma experienced by psychiatric patients in a Southeast Asian city. Our aim was to compare the stigma experienced by psychiatric patients with a control group comprising medical outpatients in various domains of their lives e.g. socializing with friends, applying for jobs, applying for training and education, having close personal relationships, and the like.

We hypothesise that psychiatric patients experience higher levels of stigma in the form of discrimination than controls, and that a higher proportion of psychiatric patients practice non-disclosure of their illness when compared to controls.

\section{Methodology}

\subsection{Participants and Procedure}

The study was conducted in a specialist outpatient clinic of the Singapore General Hospital (SGH), a large public, tertiary care, teaching hospital. Singapore is a modern city state in Southeast Asia, located at the southern tip of the Malaysian peninsula. Participants were recruited from 2 January-30 April 2017. Patients whose names appeared on clinic lists were assigned numbers. Those whose numbers were randomly selected by computer were approached for consent to participate in the study. All psychiatric patients, between the ages of 21 and 65, were included, while those with organic mental disorders e.g. dementia and delirium were excluded. The main diagnostic categories were anxiety disorders, stressor-related disorders, depressive disorders, obsessive-compulsive and related disorders based on DSM-5 criteria. Control patients comprised patients attending for medical outpatient treatment in the same general hospital. They should be between ages 21 to 65 . Their main diagnoses were diabetes, hypertension, respiratory, and gastrointestinal disorders. We did not approach patients from the Department of Infectious Diseases in order to avoid recruiting patients with sexually transmitted diseases, who could also be victims of stigma. All patients were approached with the approval of their respective consultants, and enrolled after giving writ- 
ten informed consent. Ethical approval was obtained from the hospital's Institutional Review Board.

\subsection{Materials}

Psychiatric outpatients and controls were assessed for experienced discrimination through a structured questionnaire that included items adapted from the Discrimination and Stigma Scale (DISC-12) [19] and the 10-item Rosenberg Self-Esteem Scale to assess level of self-esteem [20], as well as items ascertaining demographic and clinical details. Self-esteem data will not be presented in this paper. Controls were assessed using the same questionnaire, with items being modified to assess discrimination attributed to physical, rather than mental health problems.

\subsection{Statistical Analysis}

Postulating a moderate difference in levels of stigma experienced by psychiatric patients and controls with a Cohen's effect size of 0.5 , for a power of $80 \%$ with a 2 -sided test of $5 \%$ to achieve a statistically significant result, a minimum of 65 subjects in each group would be required. Data was analysed using the Statistical Package for the Social Sciences (SPSS) 22.0. Differences in numerical demographic variables and the levels of experienced discrimination between psychiatric patients and controls were analysed using one-way ANOVA when normality and homogeneity assumptions were satisfied, otherwise the Kruskal Wallis test was performed; and for categorical variables, the Pearson's chi-squared test was used. Significance was set at $p<0.05$.

\section{Results}

A total of 202 patients comprising 99 psychiatric patients and 103 medical patients gave consent to the study (response rate: 69\% psychiatric patients vs $72 \%$ controls).

The majority of the psychiatric patients suffered from mood and anxiety disorders according to DSM-5 criteria [21]. There appeared to be no significant sociodemographic differences between psychiatric patients and controls (see Table 1).

As Table 2 suggests, psychiatric patients were more likely to report experiencing discrimination than controls in various domains of life (in all cases, $p<$ $0.05)$, the only exception concerning perceived discrimination by spouse, where there was no significant difference between psychiatric patients and controls ( $p$ $=0.063$ ). When patients were asked to rate their experience of discrimination on a 4-point Likert scale (not at all, a little, moderately, and a lot, which served as an indicator of severity), one-way ANOVA conducted on the "severity" scores revealed that psychiatric patients experienced higher levels of discrimination than controls $(F(1,196)=24.4, p<0.001)$, and that they perceived discrimination in more areas of life than controls $(F(1,196)=22.5, p<0.001)$. For example, in the area of making and/or keeping friends $(29.4 \%$ vs $6.4 \%, p=0.002)$, applying for 
education $(35.4 \%$ vs $8.8 \%, p=0.036)$, and in keeping a job $(32.2 \%$ vs $5.8 \%, p=$ $0.001)$.

Regarding non-disclosure, compared to controls, psychiatric patients were significantly more likely to avoid discussing their mental health problem $(\mathrm{OR}=14.49$, $p<0.001,95 \%$ confidence interval (CI) $7.14-29.41$ ), and were also more likely to feel embarrassed about disclosing that they were receiving psychiatric treatment (OR $=11.63, p<0.001,95 \%$ CI $5.81-23.26)$. In fact, $66.7 \%$ psychiatric patients vs $14.7 \%$ controls reported feeling embarrassed at the idea of disclosing they were receiving treatment $(p<0.001)$.

As seen in Table 3, psychiatric patients were more likely than controls to Table 1. Demographic characteristics of patients.

\begin{tabular}{|c|c|c|c|c|c|}
\hline & \multicolumn{2}{|c|}{ Psychiatric Patients } & \multicolumn{2}{|c|}{ Non-Psychiatric Patients } & \multirow[b]{2}{*}{$p$-value } \\
\hline & $\begin{array}{l}\text { Number } \\
(N=99)\end{array}$ & $\begin{array}{c}\text { Percentage } \\
(\%)\end{array}$ & $\begin{array}{l}\text { Number } \\
(N=102)\end{array}$ & $\begin{array}{c}\text { Percentage } \\
(\%)\end{array}$ & \\
\hline Gender & & & & & 0.915 \\
\hline Female & 58 & 58.6 & 59 & 57.8 & \\
\hline Age & & & & & 0.921 \\
\hline Mean (Standard Deviation) & \multicolumn{2}{|c|}{$42(12.5)$} & \multicolumn{2}{|c|}{$41.8(11.5)$} & \\
\hline Median (Range) & \multicolumn{2}{|c|}{$43(21-65)$} & \multicolumn{2}{|c|}{$43(21-62)$} & \\
\hline Education Level & & & & & 0.238 \\
\hline Primary to Secondary & 33 & 33.3 & 24 & 23.6 & \\
\hline Junior College/Polytechnic & 30 & 30.3 & 27 & 26.5 & \\
\hline University & 36 & 36.4 & 51 & 50 & \\
\hline Employment Status & & & & & 0.495 \\
\hline Employed & 75 & 75.8 & 83 & 81.4 & \\
\hline Unemployed & 10 & 10.1 & 5 & 4.9 & \\
\hline Not in Labour Force & 14 & 14.1 & 14 & 13.7 & \\
\hline Marital Status & & & & & 0.164 \\
\hline Never Married & 48 & 48.5 & 36 & 35.3 & \\
\hline Married & 46 & 46.5 & 60 & 58.8 & \\
\hline Divorced or Separated & 5 & 5.1 & 6 & 5.9 & \\
\hline Widowed & 0 & 0 & 0 & 0 & \\
\hline Religion & & & & & 0.286 \\
\hline Christianity & 29 & 29.3 & 28 & 27.5 & \\
\hline Islam & 8 & 8.1 & 10 & 9.8 & \\
\hline Buddhism/Taoism & 39 & 39.4 & 35 & 34.3 & \\
\hline Hinduism & 3 & 3.0 & 10 & 9.8 & \\
\hline Others & 2 & 2.0 & 0 & 0 & \\
\hline No Religion & 18 & 18.2 & 19 & 18.6 & \\
\hline
\end{tabular}


Table 2. Experienced discrimination in areas of life due to mental or physical health problem.

\begin{tabular}{cccccc}
\hline & \multicolumn{3}{c}{ Psychiatric Patients } & Non-Psychiatric Patients & \\
\cline { 2 - 5 } Area of Life & $\begin{array}{c}\text { Number, } \\
\text { Total } N\end{array}$ & $\begin{array}{c}\text { Percentage } \\
(\%)\end{array}$ & $\begin{array}{c}\text { Number, } \\
\text { Total } N\end{array}$ & $\begin{array}{c}\text { Percentage } \\
(\%)\end{array}$ & $p$-value \\
\hline In making/keeping friends & 20,68 & 29.4 & 5,78 & 6.4 & 0.002 \\
In dating/intimate relationships & 13,33 & 39.4 & 2,60 & 13.0 & 0.006 \\
In your education & 11,31 & 35.5 & 3,34 & 8.8 & 0.036 \\
In the course of marriage, by your spouse & 8,42 & 19.0 & 2,60 & 3.3 & 0.063 \\
By your own family & 27,83 & 32.5 & 10,86 & 11.6 & 0.005 \\
In finding a job & 13,25 & 52.0 & 3,32 & 9.4 & 0.001 \\
In keeping a job & 18,56 & 32.1 & 4,69 & 5.8 & 0.001 \\
In getting welfare benefits & 13,26 & 50.0 & 5,28 & 17.9 & 0.036 \\
In your social life & 26,73 & 35.6 & 11,74 & 14.9 & 0.003 \\
By physical health professionals & 21,72 & 29.2 & 5,84 & 6.0 & 0.001 \\
\hline
\end{tabular}

Note: Different Total $N$ as different numbers of participants disclosed their mental or physical health problem in each area of life.

Table 3. Non-disclosure and activities avoided by psychiatric patients and controls.

\begin{tabular}{|c|c|c|c|c|c|}
\hline & \multicolumn{2}{|c|}{ Psychiatric Patients } & \multicolumn{2}{|c|}{ Non-Psychiatric Patients } & \multirow{3}{*}{$p$-value } \\
\hline & Number & $\begin{array}{c}\text { Percentage } \\
(\%)\end{array}$ & Number & $\begin{array}{c}\text { Percentage } \\
(\%)\end{array}$ & \\
\hline Non-Disclosure towards & \multicolumn{2}{|c|}{ (Total $N=72$ ) } & \multicolumn{2}{|c|}{ (Total $N=15)$} & \\
\hline Family & 23 & 31.9 & 4 & 26.7 & 0.688 \\
\hline Friends & 54 & 75 & 8 & 53.3 & 0.092 \\
\hline Employers & 39 & 54.2 & 5 & 33.3 & 0.142 \\
\hline Colleagues & 50 & 69.4 & 5 & 33.3 & 0.008 \\
\hline Family doctor/any other doctors & 7 & 9.7 & 0 & 0 & 0.208 \\
\hline Counsellors & 3 & 4.2 & 0 & 0 & 0.421 \\
\hline Religious associates & 12 & 16.7 & 1 & 6.7 & 0.323 \\
\hline Activities Avoided & $\begin{array}{l}\text { (Number, } \\
\text { Total } N \text { ) }\end{array}$ & & $\begin{array}{c}\text { (Number, } \\
\text { Total } N \text { ) }\end{array}$ & & \\
\hline Socialising with friends & 37,92 & 40.2 & 6,96 & 6.3 & $<0.001$ \\
\hline Applying for jobs & 23,49 & 46.9 & 5,43 & 11.6 & 0.002 \\
\hline Applying for education/training & 16,49 & 32.7 & 5,49 & 10.2 & 0.005 \\
\hline Having a close personal relationship & 29,29 & 36.7 & 4,87 & 4.5 & $<0.001$ \\
\hline
\end{tabular}

avoid disclosing their illness to their colleagues $(p=0.008)$. Both psychiatric and medical patients were as likely to avoid disclosure to their employers $(p=0.142)$. Conversely, psychiatric patients were more likely than controls to disclose their 
Table 4. Reasons for feeling embarrassed about disclosing mental or physical health treatment.

\begin{tabular}{cccccc}
\hline & \multicolumn{2}{c}{ Psychiatric Patients } & Non-Psychiatric Patients & \\
\cline { 2 - 5 } Reason for Embarrassment & $\begin{array}{c}\text { Number } \\
(N=65)\end{array}$ & $\begin{array}{c}\text { Percentage } \\
(\%)\end{array}$ & $\begin{array}{c}\text { Number } \\
(N=15)\end{array}$ & $\begin{array}{c}\text { Percentage } \\
(\%)\end{array}$ & $p$-value \\
\hline People might reject me & 42 & 64.6 & 4 & 26.7 & 0.007 \\
I may not find a spouse & 14 & 21.5 & 0 & 0 & 0.048 \\
$\quad$ I will lose my job & 37 & 56.9 & 3 & 20 & 0.010 \\
I will not be able to buy & 22 & 33.8 & 2 & 13.3 & 0.118 \\
an insurance policy & 29 & 44.6 & 3 & 20 & 0.079 \\
\hline \begin{tabular}{c} 
People might make fun of me \\
\hline
\end{tabular}
\end{tabular}

condition to their counsellors $(p=0.001)$.

Compared to medical patients, psychiatric patients were more likely to avoid socializing with friends, applying for jobs, applying for higher education, and avoiding close personal relationships (please refer to Table 3).

Reasons psychiatric patients gave for avoiding illness and treatment disclosure are listed in Table 4. Psychiatric patients were more likely than controls to avoid illness and treatment disclosure for fear of spoiling their chances of finding a spouse, of being rejected, and of losing their jobs $(p<0.05)$. There were no differences between psychiatric patients and controls with regard to not being able to purchase insurance policies, or the fear that people might make fun of them $(p>0.05)$.

Psychiatric patients who did not disclose their psychiatric problems were more likely than controls to have experienced higher levels of discrimination ( $F$ $(1,95)=6.55, p=0.012)$, and those who felt embarrassed or uncomfortable about self-disclosure experienced higher levels of discrimination than those who did not feel embarrassment or discomfort regarding disclosure $(F(1,97)=6.56$, $p=0.012)$.

\section{Discussion}

Stigma is a complex phenomenon that arises from past experiences of discrimination and the anticipation of future discrimination by others [9] [10]. Our findings suggest that patients coped with discrimination by non-disclosure of their illness, a widely reported coping strategy [22] [23] [24].

Disclosure avoidance was also associated with higher levels of past discrimination, as our findings seem to suggest. Previous negative reactions to disclosure could also predispose to fear of future discrimination, as observed by Lasalvia [25]. Conversely, it has been reported that greater comfort in disclosing one's mental illness was associated with lower anticipated discrimination [23].

Notwithstanding psychiatric patients' reluctance at disclosure, there were some who did share information about themselves, despite some embarrassment. Unfortunately, those who disclosed their illness and treatment were still more likely 
than controls to report experiencing negative reactions from those they confided in. It is plausible that such negative reactions might have caused deep embarrassment, thus curbing further disclosure.

Some hold that the fear of future discrimination may have a greater impact on disclosure than discrimination experienced in the past [10] [25] [26], whereas our findings suggest the reverse i.e. a higher level of past discrimination predisposing to anticipated discrimination. Lasalvia et al. [10] found that anticipated discrimination was not necessarily associated with past discrimination as almost nearly half their cohort had not experienced discrimination. This observation did not seem to hold true in our case.

Although some $43 \%$ of our psychiatric patients were prepared to disclose details of their mental illness to their medical doctors, this contrasted with patients in Taiwan, where only $5.7 \%$ actually communicated their mental health concerns, and $12.3 \%$ were willing to talk about their mental health problems to their physicians [27]. Perhaps in our patients, disclosure to medical doctors (which included family physicians or primary care physicians) was considered necessary in order to seek specialist referral to the psychiatric services.

While most non-disclosure could be attributed to fear of stigma, some [28] have argued that the reasons for non-disclosure especially to primary care doctors could be viewed more accurately as a problem of "alternative taxonomic systems" than of fear of stigma. Rather than expressing psychological symptoms, persons with anxiety and depression could have expressed their concerns in the form of physical symptoms rather than psychological ones [28]. This suggests that psychiatric patients assumed that their physicians were more interested in their physical rather than in their psychological symptoms.

Our medical and psychiatric patients' reluctance to share information about their diagnoses to their employers arose from fear of jeopardizing their careers. Of those who did confide in their employers, there was a trend for controls to be more willing than psychiatric patients to self-disclose. This suggests that the fear of discrimination and of job jeopardy was greater among psychiatric patients than in controls. In the case of job applicants, reasons for concealment include the fear that they would not be hired if they self-disclosed [29]. Our findings also suggest that psychiatric patients were more likely to withhold information about their illness and treatment from colleagues. Possible reasons have included anticipation of unfair treatment in the workplace, the fear of losing credibility, gossip, and possible rejection [29].

The subtheme, "wouldn't be hired if psychiatric condition disclosed" very much reflects our local situation, as in the case of others [30] [31]. Stigmatizing attitudes by employers make it difficult for persons with mental illness to find employment [30]. Compared with individuals with physical disorders, twice as many people with psychiatric conditions expect to experience employment-related stigma [32], with one in three persons with mental illness in the United States turned down for a job once their psychiatric status became known [31]. This is 
because employers are less likely to hire people known to have a history of mental illness [30] [33] [34].

That psychiatric patients experienced more stigma than controls was expected and confirmed our study hypothesis. Although there was initial reluctance during dating to self-disclose, those who did marry did not report higher level of discrimination by spouses, an encouraging finding which suggests that most spouses are aware of and accept patients' illness and could serve as an effective source of support. Elsewhere, Lauber and Rossler [16] found that mentally ill persons and their families face social disapproval, and that this has repercussions with regard to marriage, marital separation, and divorce.

There appeared to be similarities between psychiatric and medical patients' anxieties about not being able to purchase insurance policies. Any pre-existing illness, psychiatric or medical, is likely to attract higher premiums or result in ineligibility from purchasing insurance coverage. These are valid apprehensions. In the case of psychiatric patients, such ineligibility could possibly reflect discrimination by the insurance industry towards persons with mental illness. It is also understandable that both sets of patients would likely express apprehension about being the subject of ridicule should their illnesses be revealed to work colleagues. This is especially so if they are perceived as being less capable of performing as efficiently or as competently as their co-workers.

\section{Strengths and Limitations}

To our knowledge, our study is one of the very few to report stigma experienced by psychiatric patients in a Southeast Asian outpatient setting. Conducted in a busy general hospital, we were able to recruit more than required numbers of both sets of patients for meaningful analyses to be performed. An established instrument we used e.g. the DISC-12 could potentially allow comparisons with other studies to be made.

Although our hypotheses were confirmed, there are several limitations worth noting. Our findings were confined to a single study site, and it is uncertain whether the results can be generalizable to other centers in the country. As our hospital does not practise a strict catchment area policy, patients living in different parts of the country could attend for treatment in our hospital. Hence, it is possible that our psychiatric cohort could be similar in demographic characteristics from patients from other treatment centers. Another limiting factor concerns the relatively few patients with psychoses who attend our outpatient clinics. Hence, our findings are limited to those suffering from mood and anxiety conditions. Nevertheless, it is possible that the experience of stigma would be even more keenly felt had more psychotic patients been recruited into the study.

\section{Conclusion}

Stigma remains a major problem among anxious and depressed patients, with discrimination experienced in most social domains. Although disapproval from 
family members of psychiatric patients was significant, this did not extend to discrimination from spouses. Psychiatric patients coped by withholding information about their illness. Both groups avoided disclosure to employers, with psychiatric patients more likely to avoid disclosure to colleagues. That psychiatric patients experience higher levels of stigma emphasizes a need for anti-stigma campaigns, continued psycho-education of patients and the public, as well as the passing of strict anti-stigma legislation. This is essential in creating a supportive environment that encourages understanding and acceptance of psychiatric patients in various areas of life.

\section{Acknowledgements}

We thank CCH See, D Wong, and SY Au for their contributions in data gathering.

\section{References}

[1] Johnstone, M.J. (2001) Stigma, Social Justice and the Rights of the Mentally Ill: Challenging the Status Quo. International Journal of Mental Health Nursing, 10, 200-209. https://doi.org/10.1046/j.1440-0979.2001.00212.x

[2] Link, B.G., Cullen F.T. and Wozniak, J.F. (1987) The Social Rejection of Former Mental Patients: Understanding Why Labels Matter. American Journal of Sociology, 92, 1461-1500. https://doi.org/10.1086/228672

[3] Penn, D.L., Guynan, K., Daily, T., et al. (1994) Dispelling the Stigma of Schizophrenia: What Sort of Information Is Best? Schizophrenia Bulletin, 20, 567-578. https://doi.org/10.1093/schbul/20.3.567

[4] Socall, D.W. and Holtgraves, T. (1992). Attitudes toward the Mentally Ill: The Effects of Label and Beliefs. The Sociological Quarterly, 33, 435-445. https://doi.org/10.1111/j.1533-8525.1992.tb00383.x

[5] Bellack, A.S., Mueser, K.T., Morrison, R.L., Tierney, A. and Podell, K. (1990) Remediation of Cognitive Deficits in Schizophrenia. American Journal of Psychiatry, 147, 650-655.

[6] Mueser, K.T., Bellack, A.S., Douglas, M.S. and Morrison, R.L. (1991) Prevalence and Stability of Social Skill Deficits in Schizophrenia. Schizophrenia Research, 5, 167-176. https://doi.org/10.1016/0920-9964(91)90044-R

[7] Eagly, A.H., Ashmore, R.D., Makhijani, M.G., et al. (1991) What Is Beautiful Is Good, But...: A Meta-Analytic Review of Research on the Physical Attractiveness Stereotype. Psychological Bulletin, 110, 109-128.

https://doi.org/10.1037/0033-2909.110.1.109

[8] Penn, D.L., Mueser, K.T. and Doonan, R. (1997) Physical Attractiveness in Schizophrenia: The Mediating Role of Social Skill. Behavior Modification, 21, 78-85. https://doi.org/10.1177/01454455970211004

[9] Thornicroft, G., Brohan, E., Rose, D., Sartorius, N., Leese, M. and INDIGO Study Group (2009) Global Pattern of Experienced and Anticipated Discrimination against People with Schizophrenia: A Cross-Sectional Survey. Lancet, 373, 408-415. https://doi.org/10.1016/S0140-6736(08)61817-6

[10] Lasalvia, A., Zoppei, S., van Bortel, T., et al. (2013) Global Pattern of Experienced and Anticipated Discrimination Reported by People with Major Depressive Disorder: A Cross-Sectional Survey. Lancet, 381, 55-62. 


\section{https://doi.org/10.1016/S0140-6736(12)61379-8}

[11] Corker, E.A., Beldie, A., Brain, C., et al. (2015) Experience of Stigma and Discrimination Reported by People Experiencing the First Episode of Schizophrenia and Those with a First Episode of Depression: The FEDORA Project. International Journal of Social Psychiatry, 61,438-445. https://doi.org/10.1177/0020764014551941

[12] Barney, L.J., Griffiths, K.M., Jorm, A.F. and Christensen, H. (2006) Stigma about Depression and Its Impact on Help-Seeking Intentions. Australian and New Zealand Journal of Psychiatry, 40, 51-54. https://doi.org/10.1080/j.1440-1614.2006.01741.x

[13] Sartorius, N. (2007) Stigma and Mental Health. Lancet, 370, 810-811. https://doi.org/10.1016/S0140-6736(07)61245-8

[14] Thornicroft, G. (2007) Most People with Mental Illness Are Not Treated. Lancet, 370, 807-808. https://doi.org/10.1016/S0140-6736(07)61392-0

[15] Rusch, N., Angermeyer, M.C. and Corrigan, P.W. (2005) The Stigma of Mental Illness: Concepts, Forms, and Consequences. Psychiatrische Praxis, 32, 221-232.

[16] Lauber, C. and Rössler,W. (2007) Stigma towards People with Mental Illness in Developing Countries in Asia. International Review of Psychiatry, 19, 157-178. https://doi.org/10.1080/09540260701278903

[17] Chong, S.A., Verma, S., Vaingankar, J.A., et al. (2007) Perception of the Public towards the Mentally Ill in a Developed Asian Country. Social Psychiatry and Psychiatric Epidemiology, 42, 734-739. https://doi.org/10.1007/s00127-007-0213-0

[18] Subramaniam, S., Abdin, E., Picco, L., et al. (2016) Stigma towards People with Mental Disorders and Its Components-A Perspective from Multi-Ethnic Singapore. Epidemiology and Psychiatric Sciences, 1, 1-12.

[19] Brohan, E., Clement, S., Rose, D., Sartorius, N., Slade, M. and Thornicroft, G. (2013) Development and Psychometric Evaluation of the Discrimination and Stigma Scale (DISC). Psychiatry Research, 30, 33-40. https://doi.org/10.1016/j.psychres.2013.03.007

[20] Rosenberg, M. (1989) Society and the Adolescent Self-Image. Revised Edition, Wesleyan University Press, Middletown.

[21] American Psychiatric Association (2013) Diagnostic and Statistical Manual of Mental Disorders: DSM-5. American Psychiatric Association, Washington DC. https://doi.org/10.1176/appi.books.9780890425596

[22] Barke, A., Nyarko, S. and Klecha, D. (2011) The Stigma of Mental Illness in Southern Ghana: Attitudes of the Urban Population and Patients' Views. Social Psychiatry and Psychiatric Epidemiology, 46, 1191-1202. https://doi.org/10.1007/s00127-010-0290-3

[23] Rüsch, N., Brohan, E., Gabbidon, J., Thornicroft, G. and Clement, S. (2014) Stigma and Disclosing One's Mental Illness to Family and Friends. Social Psychiatry and Psychiatric Epidemiology, 49, 1157-1160. https://doi.org/10.1007/s00127-014-0871-7

[24] Reavley, N.J., Morgan, A.J. and Jorm, A.F. (2017) Disclosure of Mental Health Problems: Findings from an Australian National Survey. Epidemiology and Psychiatric Sciences, 11, 1-11. https://doi.org/10.1017/S204579601600113X

[25] Lasalvia, A., Zoppei, S., Bonetto, C., et al. (2014) The Role of Experienced and Anticipated Discrimination in the Lives of People with First-Episode Psychosis. Psychiatric Services, 65, 1034-1040. https://doi.org/10.1176/appi.ps.201300291

[26] Oshodi, Y.O., Abdulmalik, J., Ola, B., et al. (2014) Pattern of Experienced and An- 
ticipated Discrimination among People with Depression in Nigeria: A Cross-Sectional Study. Social Psychiatry and Psychiatric Epidemiology, 49, 259-266.

https://doi.org/10.1007/s00127-013-0737-4

[27] Han, D.Y., Lin, Y.Y., Liao, S.C., Lee, M.B., Thornicroft, G. and Wu, C.Y. (2015) Analysis of the Barriers of Mental Distress Disclosure in Medical Inpatients in Taiwan. International Journal of Social Psychiatry, 61, 446-455. https://doi.org/10.1177/0020764014552865

[28] Prior, L., Pang, L.C. and See, B.H. (2000) Beliefs and Accounts of Illness. Views from Two Cantonese Speaking Communities in England. Sociology of Health and Illness, 22, 815-839. https://doi.org/10.1111/1467-9566.00232

[29] Brohan, E., Henderson, C., Wheat, K., et al. (2012) Systematic Review of Beliefs, Behaviours and Influencing Factors Associated with Disclosure of a Mental Health Problem in the Workplace. BMC Psychiatry, 12, 11. https://doi.org/10.1186/1471-244X-12-11

[30] Stuart, H. (2006) Mental Illness and Employment Discrimination. Current Opinion in Psychiatry, 19, 522-526. https://doi.org/10.1097/01.yco.0000238482.27270.5d

[31] Wahl, O.F. (1999) Mental Health Consumers' Experiences of Stigma. Schizophrenia Bulletin, 25, 467-478. https://doi.org/10.1093/oxfordjournals.schbul.a033394

[32] Roeloffs, C., Sherbourne, C., UnÜtzer, A., et al. (2003) Stigma and Depression among Primary Care Patients. General Hospital Psychiatry, 25, 311-315. https://doi.org/10.1016/S0163-8343(03)00066-5

[33] Bordieri, J. and Drehmer, D. (1986) Hiring Decision for Disabled Workers: Looking at the Cause. Journal of Applied Social Psychology, 16, 197-208. https://doi.org/10.1111/j.1559-1816.1986.tb01135.x

[34] Corrigan, P.W. and Penn, D.L. (1999) Lessons from Social Psychology on Discrediting Psychiatric Stigma. American Psychologist, 54, 765-776.

https://doi.org/10.1037/0003-066X.54.9.765 